\title{
Assessment of hypoglycemic symptoms in insulin-treated adults with diabetes mellitus
}

\section{Mohammad Alkhatatbeh, Nedaa A. Abdelqader and Mohammad A. Alqudah}

Clinical Pharmacy Department, Faculty of Pharmacy, Jordan University of Science and Technology, Irbid, Jordan

\section{Background}

Diabetes mellitus (DM) is a chronic endocrine disorder that is characterized by hyperglycemia as a result of insulin deficiency (type 1) or insulin resistance (type 2). Insulin is used for type $1 \mathrm{DM}$ and it can be used for type
$2 \mathrm{DM}$ in addition to oral hypoglycemic medications. Appropriate insulin regimens along with life style 2 DM in addition to oral hypoglycemic medications. Appropriate insulin regimens along with life style
modifications should maintain a state of euglycemia with minimal hyperglycemic or hypoglycemic episodes to modifications should maintain a state of euglycemia with minimal hyperglycemic or hypoglycemic episodes to protect from the development of diabetic complications. Hypoglycemia is considered more severe than hyperglycemia as the former enhances the release of glucagon and other counter regulatory hormones resulting in acute sympathetic and neuroglycopenic symptoms that may lead to coma. Fortunately, patients can feel these symptoms and thus self-treat themselves by taking a source of sugar. Adversely, frequent episodes of hypoglycemia may decrease the recognition of the hypoglycemic symptoms resulting in a condition called Impaired Awareness of Hypoglycemia (IAH).

\section{Aims}

To assess the frequency of hypoglycemic episodes, awareness of hypoglycemic symptoms, intensity of hypoglycemic symptoms, and the association between level of hypoglycemic awareness and other measurements including type of DM, duration of DM, duration of insulin therapy, and frequency of hypoglycemia among insulin-treated diabetic adults.

\section{Methods}

Study design. Insulin-treated type 1 and type 2 DM patients were recruitted from the diabetic clinic of King Abdullah University Hospital in Jordan. Patients who were on oral hypoglycemic medications were excluded from the study. Patients were asked to report the number of their hypoglycaemic episodes in the past month and 6 months. The intensity of hypoglycemic symptoms was assessed using the validated Edinburgh hypoglycemia survey [1] and the awareness of hypoglycemia was assessed using Clarke's hypoglycemia survey [2].

Statistical analysis. Statistical analysis was performed using IBM SPSS statistics version 20 (Armonk, New York, USA). Data were expressed as number of participants (\%), mean \pm standard deviation (SD) or median $\left(25^{\text {th }}-75^{\text {th }}\right.$ percentiles) as appropriate. Differences in qualitative variables were determined using Chi-square test or Fisher's exact test as appropriate ( $p$-values $<0.05$ were considered statistically significant).

\section{Results}

Data were collected from 410 insulin-treated adults (94.6\% type 2 and $5.4 \%$ type 1 DM) from both genders $(46.6 \%$ males and $53.4 \%$ females) with an average $( \pm S D)$ age of $57.63( \pm 13.45)$ years. The average $( \pm S D)$ duration of DM was $14.78( \pm 7.36)$ years, the median $\left(25^{\text {th }}-75^{\text {th }}\right.$ percentiles $)$ duration of insulin therapy was $4.0(2.0-7.0)$ years, and the average $( \pm \mathrm{SD})$ of glycated hemoglobin (HbA1C) was $9.32 \%( \pm 2.17 \%)$.

\section{Table 1: Patients' characteristics}

\begin{tabular}{lll}
\hline Variable & Value \\
\hline Type of DM & $22(5.4)$ \\
\hline Type 1 & $388(94.6)$ \\
\hline Type 2 & $57.63 \pm 13.45$ \\
\hline Age (Years) & $191(46.6)$ \\
\hline Gender & $219(53.4)$ \\
Male & $30.28 \pm 5.37$ \\
Female & $58(14.1)$ \\
\hline BMI & $118(28.8)$ \\
\hline Level of education & $154(37.6)$ \\
\hline $\begin{array}{l}\text { Not educated } \\
\text { Primary school }\end{array}$ & $80(19.5)$ \\
\hline Secondary school & $5.0(3.5-6.0)$ \\
High university education & \\
\hline Number of family members & $328(80)$ \\
\hline Average family income (JD) & $82(20)$ \\
$\leq 500$ & $14.78 \pm 7.36$ \\
$>500$ & $4.0(2.0-7.0)$ \\
\hline Duration of DM (Years) & $9.32 \pm 2.17$ \\
\hline Duration of insulin therapy (Year) & \\
\hline HbA1c (\%) & Data are presented as number of participants (\%), mean \pm standard deviation (SD) or median \\
\hline
\end{tabular}

Data are presented as number of participants (\%), mean \pm standard deviation (SD) or median

$\left(25^{\text {th }}-75^{\text {th }}\right.$ percentiles) as appropriate

48.8\% of participants did not develop any hypoglycemic episode that was associated with hypoglycemic symptoms during the last month while $42.2 \%, 3.2 \%, 3.9 \%$ and $2 \%$ of them had developed $1-3$ hypoglycemic episodes, one hypoglycemic episode weekly, 2-3 hypoglycemic episodes weekly and 4-5 hypoglycemic episodes weekly, respectively.

Figure 1: Frequency of blood glucose measurement $<70 \mathrm{mg} / \mathrm{dL}$ during the last month with symptoms

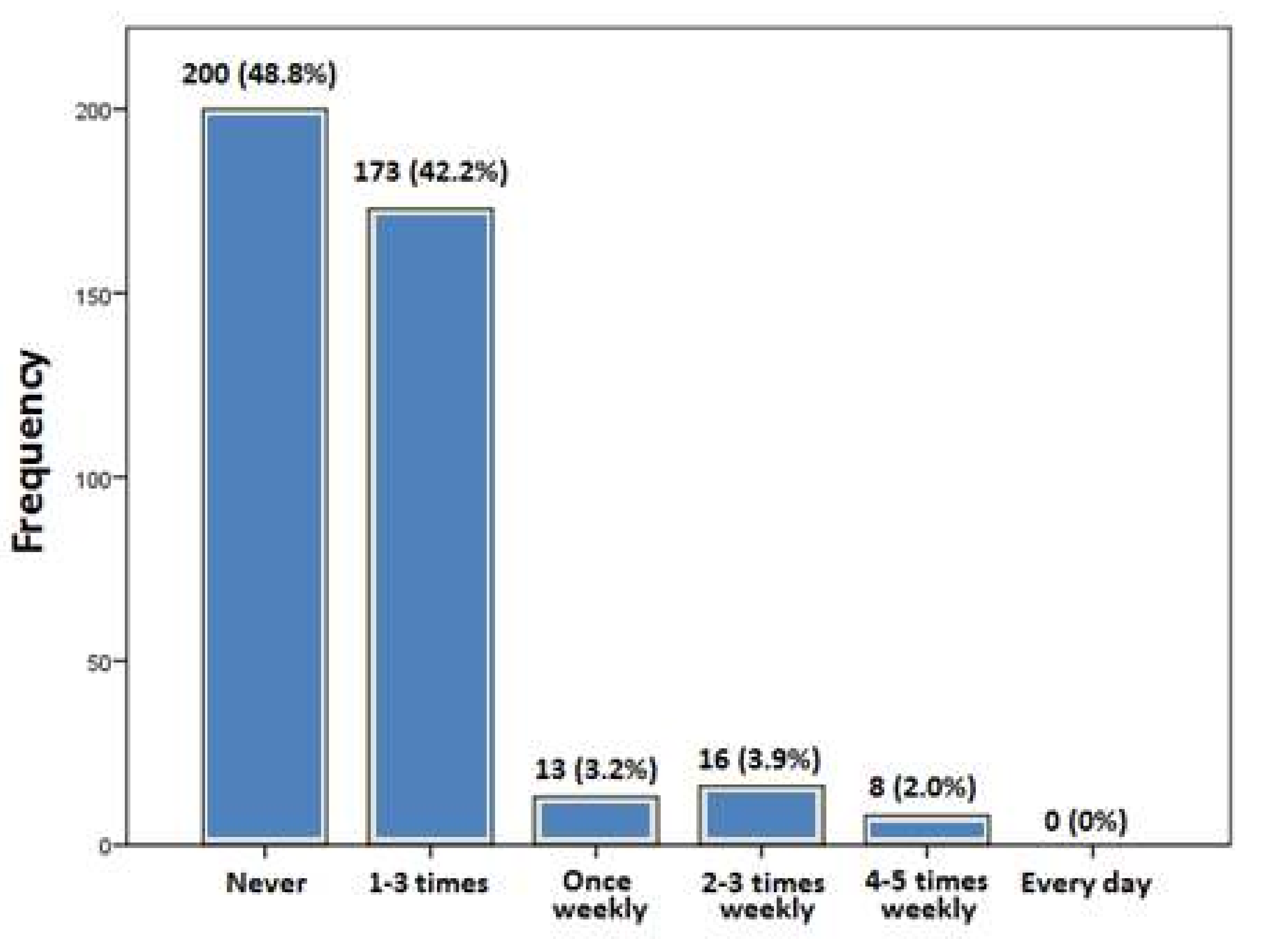

Results

According to Clarke's hypoglycemia survey, $81 \%$ of participants were classified as being aware of hypoglycemic symptoms and $19 \%$ were classified as having impaired awareness of hypoglycemia.

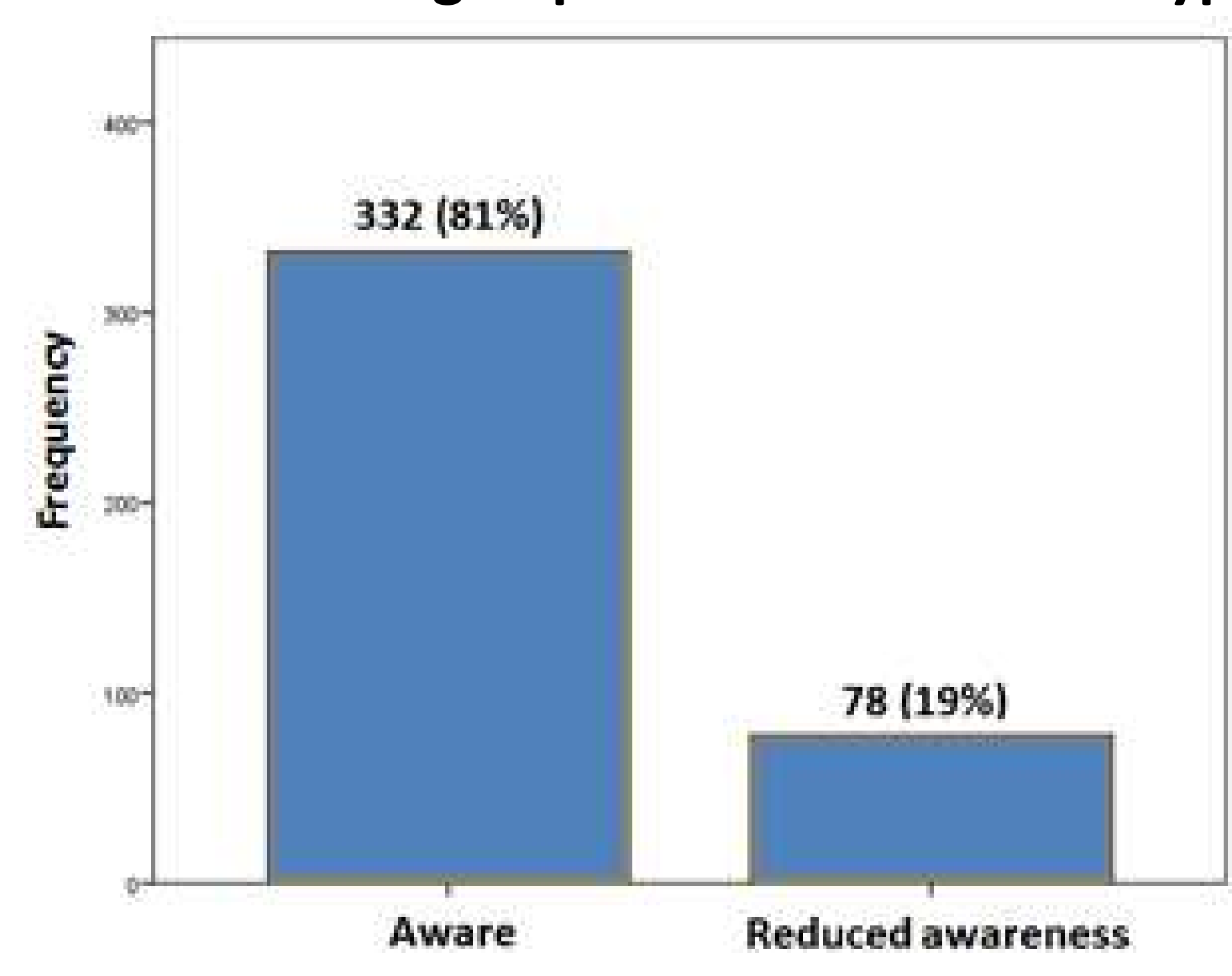

Figure 2: Level oh hypoglycemic awareness defined by Clarke's method

Level of hypoglycemic awareness was significantly dependent on the type of DM, body mass index (BMI), duration of DM, duration of insulin therapy and frequency of hypoglycemia during the past 6 months.

Table 2: Dependence of hypoglycemia awareness on different variable

\begin{tabular}{|c|c|c|c|}
\hline & Aware $(n=332)$ & $\begin{array}{l}\text { Reduced awareness }(n= \\
\text { 78) }\end{array}$ & P-value* \\
\hline \multicolumn{4}{|l|}{ Type of DM } \\
\hline Type 1 & $10(3.0)$ & $12(15.4)$ & \multirow[t]{2}{*}{0.00} \\
\hline Type 2 & $322(97.0)$ & $66(84.6)$ & \\
\hline \multicolumn{4}{|l|}{ Gender } \\
\hline Male & $151(45.5)$ & $40(51.3)$ & \multirow[t]{2}{*}{0.38} \\
\hline Female & $181(54.5)$ & $38(48.7)$ & \\
\hline \multicolumn{4}{|l|}{ BMI } \\
\hline Normal (18.5-25) & 46 (13.9) & $23(29.5)$ & \multirow[t]{3}{*}{0.00} \\
\hline Overweight (25-30) & $123(37.0)$ & $22(28.2)$ & \\
\hline Obese $(>30)$ & $163(49.1)$ & $33(42.3)$ & \\
\hline \multicolumn{4}{|l|}{ Level of education } \\
\hline Not educated & $51(15.4)$ & $7(9.0)$ & \multirow[t]{4}{*}{0.01} \\
\hline Primary school & $104(31.3)$ & $14(17.9)$ & \\
\hline Secondary school & $112(33.7)$ & $42(53.8)$ & \\
\hline High university education & $65(19.6)$ & $15(19.2)$ & \\
\hline \multicolumn{4}{|l|}{ Average family income (JD) } \\
\hline$\leq 500$ & $269(81.0)$ & $59(75.6)$ & \multirow[t]{2}{*}{0.35} \\
\hline$>500$ & $63(19.0)$ & $19(24.4)$ & \\
\hline \multicolumn{4}{|l|}{ Duration of DM (Year) } \\
\hline $1-5$ years & $43(13.0)$ & $2(2.6)$ & \multirow[t]{3}{*}{0.01} \\
\hline $6-10$ years & $82(24.7)$ & $27(34.6)$ & \\
\hline$>10$ years & $207(62.3)$ & $49(62.8)$ & \\
\hline \multicolumn{4}{|c|}{ Duration of insulin therapy (Year) } \\
\hline$<1$ year & $19(5.7)$ & $7(9.0)$ & \multirow[t]{4}{*}{0.046} \\
\hline $1-5$ years & $221(66.6)$ & $39(50.5)$ & \\
\hline $6-10$ years & $59(17.8)$ & $20(25.6)$ & \\
\hline$>10$ years & $33(9.9)$ & $12(15.4)$ & \\
\hline
\end{tabular}

statistically significant

Sweating, drowsiness, weakness, hunger, tiredness and trembling were the most common symptoms of hypoglycemia that were usually felt by participants when they develop hypoglycemia (median Edinburgh intensity score was 6 for all of these symptoms).

Table 3: Intensity of Hypoglycemic symptoms measured by Edinburgh survey

\begin{tabular}{lll|l|}
$\begin{array}{l}\text { Hypoglycemic } \\
\text { symptoms }\end{array}$ & $\begin{array}{l}\text { Edinburgh intensity } \\
\text { of symptom }(\mathrm{n}=410)\end{array}$ & $\begin{array}{l}\text { Hypoglycemic } \\
\text { symptoms }\end{array}$ & $\begin{array}{l}\text { Edinburgh intensity of } \\
\text { symptom }(\mathrm{n}=410)\end{array}$ \\
\hline Confusion & $4(2-6)$ & Blurred vision & $3.5(1-6)$ \\
\hline Sweating & $6(5-7)$ & Hunger & $6(5-7)$ \\
\hline Drowsiness & $6(5-7)$ & Nausea & $1(1-2)$ \\
\hline Weakness & $6(5-7)$ & Anxiety & $1(1-3)$ \\
\hline Dizziness & $2(1-6)$ & Tiredness & $6(5-6)$ \\
\hline Warmth & $2(1-4)$ & Tingling lips & $1(1-4)$ \\
\hline Difficulty in speaking & $2(1-3)$ & Trembling & $6(5-7)$ \\
\hline Pounding heart & $2(1-5)$ & Headache & $2(1-6)$ \\
\hline Inability to concentrate & $3(1-5)$ & & \\
\hline Data are expressed as median $\left(25^{\text {th }}\right.$-75 & &
\end{tabular}

\section{Discussion}

This study has reported high prevalence of hypoglycemic awareness (81\%) among insulin-treated diabetic adults. This is supported by the development of hypoglycemia that was associated with symptoms by around $50 \%$ of participants during the last month. Analysis of hypoglycemic symptoms intensity suggests that participants can recognize hypoglycemic episodes by feeling sweating, drowsiness, weakness, hunger, tiredness and trembling. The dependence of hypoglycemic awareness on the frequency of hypoglycemia suggests that the level of awareness may decrease when frequency of hypoglycemia is increased.

\section{References}

[1] Price, J., Reynolds, R., Mitchell, R., Williamson, R., Fowkes, F., Deary, I., Lee, A., Frier, B., Hayes, P. and Strachan, M. (2008). The Edinburgh Type 2 Diabetes Study: study protocol. BMC Endocrine Disorders, 8(1), p.18. [2] Clarke, W., Cox, D., Gonder-Frederick, L., Julian, D., Schlundt, D. and Polonsky, W. (1995). Reduced Awareness of Hypoglycemia in Adults With IDDM: A prospective study of hypoglycemic frequency and associated symptoms. Diabetes Care, 18(4), pp. 517-522. 